\title{
Adolescents' food habits: results of the Health Behaviour in School-aged Children survey
}

\author{
Carine A. Vereecken*, Stefaan De Henauw and Lea Maes \\ Faculty of Medicine and Health Sciences, Department of Public Health, Ghent University, De Pintelaan 185, 9000 Ghent, Belgium \\ (Received 12 May 2004 - Revised 06 April 2005 - Accepted 21 April 2005)
}

\begin{abstract}
The present study describes food habits in adolescents in thirty-five countries and regions (European countries/regions, Israel, Canada and the USA), based on the food-frequency questions from the cross-sectional Health Behaviour in School-aged Children survey of the year 2001-2. A total of 162 305 pupils of 11,13 or 15 years of age completed an anonymous standardised questionnaire on health and lifestyle factors during one school hour. Large differences in food habits between countries were found: the consumption frequency of fruit varied from on average $2 \cdot 8$ to $5 \mathrm{~d} /$ week, the consumption of vegetables varied from on average 2.4 to $5.5 \mathrm{~d}$ /week, the consumption of soft drinks varied from $2 \cdot 1$ to $5 \mathrm{~d}$ /week and sweet consumption from 2.6 to $5 \mathrm{~d}$ /week. Methodological problems in comparing between countries are discussed. Nonetheless, the results indicate a need for national and international health promotion programmes to improve adolescents' food habits.
\end{abstract}

Adolescents: Food habits: International comparison

The importance of developing healthful eating habits during childhood and adolescence is obvious. Rapid physical growth creates an increased demand for energy and nutrients (Spear, 2002). Healthy eating practices decrease young people's risk for a number of immediate health problems, such as iron deficiency anaemia, obesity, eating disorders and dental caries, and may prevent long-term health problems, such as CHD, cancer, stroke, hypertension and osteoporosis (Williams et al. 1995; Centers for Disease Control and Prevention, 1997). In addition, behaviour patterns acquired during childhood and adolescence are likely to track into adulthood (Kelder et al. 1994).

Of growing importance for public health is the surveillance of the distribution of risk factors, including nutrition, in various populations to gain information continuously for subsequent actions (Morabia, 1996).

The Health Behaviour in School-aged Children (HBSC) study is a multi-centre collaborative survey on lifestyle factors and health behaviour determinants in young people (Currie et al. 2002). This WHO-coordinated project aims to describe and understand differences in these factors between countries. An elaborated description of the overall objectives and design of this project can be found on the internet homepage: http://www. hbsc.org/.

Among many other relevant topics, a limited module of dietary habits has been incorporated in the HBSC study.

The difficulties of assessing food habits among children and adolescents are many (Rockett \& Colditz, 1997). The challenge becomes even greater when attempting to assess dietary patterns of young people across countries. The dietary assessment module used in the HBSC study can be considered a compromise between scientific desirability and practical constraints.

In view of the overall structure and context of the HBSC project, expensive, time-consuming and burdening assessment techniques, such as food diaries and repeated $24 \mathrm{~h}$ recalls, remained out of the scope of the HBSC study.

A detailed food-frequency questionnaire was also not appropriate in view of the many other questionnaire modules in the HBSC project and the wide between-country variation in the consumption of many food items.

Therefore, it has been envisaged from the very beginning of the HBSC project that only a limited list of food items, focusing on the intake of a few indicators of the adolescent's diet, would be adopted. The indicators that were identified for the 2001-2 survey through consensus discussions among all HBSC partners involved are: dietary fibre, calcium and the youth food culture.

Fat, sugar, cholesterol and sodium, though important factors in the evaluation of diet adequacy, were not included in the food questionnaire. Due to the high amount of hidden fat, sugar and sodium scattered over our meals and prepared foods, these nutrients would require too long a list of food items, not feasible within the overall scope of the HBSC study.

The aim of the food-frequency questions was not to provide quantitatively precise estimates of nutrient intakes, but to assess the intake of important sources of dietary fibre and calcium as well as the intake of a number of popular less-nutrientdense food items, in order to provide crude information on subgroup differences and trends in dietary intakes of these food items. 
Dietary fibre was selected as an important indicator of prevention of chronic degenerative diseases. Dietary fibre has been shown to reduce the risk for cancer, for CVD and for adultonset diabetes mellitus (mediated through effects on obesity, blood cholesterol level and blood glucose level). Dietary fibre, moreover, has multiple beneficial effects on the motility and functions of the gastro-intestinal system (Williams, 1995; Williams et al. 1995). The choice of calcium was predominantly based on its potential role, already during childhood and adolescence, in the prevention of osteoporosis. Calcium intake during growth may influence peak bone mass/density, and may be instrumental in preventing subsequent postmenopausal and senile osteoporosis and fracture incidence in adulthood (Matkovic \& Ilich, 1993; Bronner, 1994; Key \& Key-LL, 1994; Barr \& McKay, 1998).

For both nutrients, the intake in the youngsters is clearly a major point of public health concern. It has been reported that both dietary fibre intake (Van Poppel et al. 1991; Crawley, 1993; Doyle et al. 1994; Sargent et al. 1994; Williams, 1995; Bellu et al. 1996; Kersting et al. 1998) and calcium intake (Chan, 1991; Barr, 1994; Doyle et al. 1994; Fleming \& Heimbach, 1994; Mailhot et al. 1994; Sargent et al. 1994; Bellu et al. 1995; Buts \& Absolonne, 1995; Saldanha, 1995; Shatenstein \& Ghadirian, 1996; Albertson et al. 1997; Martinchik et al. 1997; Harel et al. 1998) of a considerable number of children in different countries on different continents is well below the recommended level.

To identify the most important sources of fibre and calcium in the diet of children and adolescents a bibliographic search was conducted for the last decade. Recurring items that contribute a substantial amount of fibre to the adolescents' diet in these studies were: bread, cereals, vegetables and fruit (Crawley, 1993; Nicklas et al. 1995; Saldanha, 1995; Subar et al. 1998). Items that contribute a substantial amount of calcium to the adolescents' diet were milk and milk products (milk drinks, yoghurt, ice cream, milkbased desserts, cheese) and grains and cereal products (Fleming \& Heimbach, 1994; Moynihan et al. 1996; Albertson et al. 1997; Subar et al. 1998).

As soft drinks and sweets, generally considered as 'empty calories' hampering intakes of more nutritious foods and hence a serious impedance for compliance with current dietary guidelines (Guenther, 1986; Harnack et al. 1999), are known to be very popular among adolescents, being typically a part of the 'youth culture', it was felt desirable to include them in the study. For the same reasons, the consumption of crisps (snack food, variously flavoured, eaten cold; US definition: potato chips) and chips (US definition: French fries) were included.

This finally resulted in a proposed list of fourteen food items. As for many countries this was still considered too much in view of the overall respondent's burden, a 'minimal' list of only four key items (from the list of fourteen) was proposed as mandatory. The 'minimal list' contained the following items: 'fruit' and 'vegetables' because of their high priority for most countries and 'non-diet soft drinks' and 'sweets (candy and chocolates)' in the context of the increasing prevalence of obesity. Ten items (light coke and soft drinks, low-fat/semi-skimmed milk, whole-fat milk, cheese, other milk products (such as yoghurt, chocolate milk, pudding, quark, etc.), cereals (such as cornflakes, muesli, choco pops, etc.), white bread, brown bread, crisps and chips) were presented as optional: participating countries can select which 'optional packages' are of most interest to be included in their national questionnaire.
In the present paper, descriptive data obtained from the dietary module in thirty-five different countries or regions during the 2001-2 HBSC survey are reported and discussed.

\section{Methodology \\ Study population and field work}

The 2001-2 HBSC survey was carried out in thirty-five countries and regions in Europe, Israel and North America. In each country/ region, cluster sampling was used, where the cluster was the class. Schools and classes within schools were selected to be representative for 11-, 13- and 15-year-old schoolchildren. The recommended minimum sample size for each country was 1536 students per age group, to assure a $95 \%$ CI of $\pm 3 \%$ for prevalence estimates, with a design factor of 1.2 based on analyses of the 1993-4 and 1997-8 surveys (Currie et al. 2002). The data were collected by means of standardised questionnaires, administered in school classrooms according to standard instructions. More detailed information about the design and methodology has been described elsewhere (Currie et al. 2002).

Table 1 provides basic information about the study population.

Seven countries/regions included the optional food-frequency package in their national surveys: Belgium (Flemish), Canada,

Table 1. Population characteristics of the study samples

\begin{tabular}{|c|c|c|}
\hline Country & $n$ & Date of data collection \\
\hline Austria & 4472 & October to November 2001 \\
\hline Belgium (Flemish) & 6289 & March to April 2002 \\
\hline Belgium (French) & 4323 & January to February 2002 \\
\hline Canada & 4361 & January to February 2002 \\
\hline Croatia & 4397 & February to March 2002 \\
\hline Czech Republic & 5012 & May 2002 \\
\hline Denmark & 4672 & January to February 2002 \\
\hline England & 6081 & March 2002 \\
\hline Estonia & 3979 & October to November 2001 \\
\hline Finland & 5388 & March to May 2002 \\
\hline France & 8185 & March to June 2002 \\
\hline Germany* & 5650 & March to May 2002 \\
\hline Greece & 3807 & October to November 2002 \\
\hline Greenland & 891 & May 2002 \\
\hline Hungary & 4164 & March to April 2002 \\
\hline Ireland & 2875 & April to June 2002 \\
\hline Israel & 5661 & May to June 2002 \\
\hline Italy & 4386 & April 2002 \\
\hline Latvia & 3481 & November to December 2001 \\
\hline Lithuania & 5645 & February to March 2002 \\
\hline Macedonia & 4161 & March 2002 \\
\hline Malta & 1980 & January 2002 \\
\hline Netherlands & 4268 & October to November 2001 \\
\hline Norway & 5023 & December 2001 \\
\hline Poland & 6383 & February to March 2002 \\
\hline Portugal & 2940 & March to April 2002 \\
\hline Russia & 8037 & March 2002 \\
\hline Scotland & 4404 & February to April 2002 \\
\hline Slovenia & 3956 & March 2002 \\
\hline Spain & 5827 & April to May 2002 \\
\hline Sweden & 3926 & November to December 2001 \\
\hline Switzerland & 4679 & March to May 2002 \\
\hline Ukraine & 4090 & February 2002 \\
\hline USA & 5025 & November to December 2001 \\
\hline Wales & 3887 & February to March 2002 \\
\hline
\end{tabular}

${ }^{*}$ A regional sample was selected in Germany (Berlin, Hessen, North Rhine-Westphalia and Saxony). 
Estonia, Greece, Latvia, Ireland and the USA. In Israel the optional package was included for half of the sample.

\section{Variables}

Students were asked how many times a week they usually eat or drink the selected food items. The response categories were 'never', 'less than once a week', 'once a week', '2-4 days a week', '5-6 days a week', 'once a day, every day', and 'more than once a day, every day'.

\section{Data analysis}

Age- and gender-standardised prevalences for the different categories of frequencies of intake of the mandatory items (fruit, vegetables, soft drink and sweets) were computed for each country and ranked according to the average weekly consumption frequency (see later).

The average weekly consumption frequency was computed by recoding the response categories as follows: 'never' $=0$, 'less than once a week' $=0 \cdot 25$ (reflecting a consumption frequency of once every 4 weeks), 'once a week' $=1$, '2-4 days a week' $=3$ (mid-point of the interval), ' $5-6$ days a week' $=5.5$ (mid-point of the interval) and 'more than once a day, every day' and 'once a day, every day' $=7$.

The optional items, collected only in the eight countries mentioned earlier, were recoded into three categories: high consumption frequency (five or more times a week), moderate consumption frequency (two to four times a week) and low consumption frequency (once a week or less).

\section{Results}

A total of 162305 pupils from thirty-five countries and regions completed the survey: $51.4 \%$ were girls; $34.1 \%$ were 11 -yearolds, $34.5 \%$ were 13 -year-olds and $31.3 \%$ were 15 -year-olds.

Fig. 1-4 show the frequency of, respectively, fruit, vegetable, soft drink and sweet consumption by country as well as the average weekly consumption (d/week) of these items. Large differences exist between the countries included in the study for all four variables. The consumption of fruit varies on average between countries from 2.8 to $5 \mathrm{~d}$ week, the consumption of vegetables from on average 2.4 to $5.5 \mathrm{~d} /$ week, the consumption of soft drinks varies from $2 \cdot 1$ to $5 \mathrm{~d}$ /week and sweet consumption from $2 \cdot 6$ to $5 \mathrm{~d} /$ week.

The lowest weekly fruit consumption frequency is found in Greenland. Spain and Malta have the lowest average vegetable consumption frequencies but also the other south European countries (Italy, Greece and Portugal) have an average consumption frequency below the median. The highest consumption frequencies of soft drinks are found in Great Britain (Scotland, Wales, England), Israel, the Netherlands, the USA, Slovenia, Belgium and Ireland.

The highest consumption frequencies of sweets are found in Ireland and Scotland.

In Table 2 the results for the optional items are presented. Also for these items, quite some variation was found.

The highest consumption frequencies of light soft drinks are found in countries that also have a high consumption frequency of regular soft drinks (Belgium (Flemish), Ireland and Israel), while the lowest consumption frequencies are found in Estonia,
Greece and Latvia: countries with a lower consumption frequency of regular soft drinks.

The between-country variation in the consumption frequencies of the milk items could partly be explained by the division of milk into (semi-)skimmed milk, whole-fat milk and other milk products. In some countries such as Belgium (Flemish) and Canada pupils mainly consume low-fat milk, while in Greece, Israel, Ireland and Estonia, the reverse is true. In the USA and Latvia the differences are small. Israel and Greece, which appear to be the higher consumers of whole-fat milk, also have the highest consumption frequency of cheese.

The lowest consumption frequencies of cereals but also the highest consumption frequencies of bread are found in Estonia and Latvia. Only in Belgium (Flemish) is the consumption frequency of brown bread higher than the consumption frequency of white bread.

In Estonia about $10 \%$ consume crisps on $\geq 5 \mathrm{~d} /$ week, in the other countries this is even more, up to $39 \%$ in Ireland. The lowest consumption frequency of chips is found in Belgium (Flemish) (3\% frequent consumers); in the USA, where fried potatoes are served as vegetables (Kubik et al. 2003), Ireland, Greece and Israel more than $20 \%$ consume chips on $\geq 5 \mathrm{~d} /$ week.

\section{Discussion}

In the past, many European countries have carried out dietary surveys among adolescents, which provide valuable information of use in local nutrition policy and practice. However, the comparability of these local efforts across countries is questionable due to differences in sampling, methodology and measurement instruments used (Cruz, 2000; Parizkova, 2000; Rolland-Cachera et al. 2000; Samuelson, 2000). The standardised methodology of the HBSC study, elaborated with a view to consistency and comparability across participating countries and across successive surveys, therefore, provides a unique opportunity to allow between-country comparisons and trend analyses.

Moreover, the incorporation of questions on eating habits in a broad health and lifestyle study significantly increases the value of the research initiatives: it offers the possibility to move beyond examining isolated risk behaviours so that broader, tailored, more effective and integrated interventions and strategies could be developed focusing on different lifestyle behaviours and/or targeting specific population groups.

The research protocol of the HBSC study has made great effort to standardise all outcome variables of the study as much as possible. Each participating country was requested to select a representative sample of each age group; all questionnaires were translated in the local language and were then back-translated to English and compared with the original standard version; specific attention was thereby given to the standardisation of the measures used in all countries; finally, data collection in the school classrooms was done within the same school year in all centres.

Nevertheless, despite the standardised methodology and measures used in all countries to collect the data, differences in consumption frequencies across countries do not necessarily reflect the real differences in consumption frequency. A number of factors could theoretically cause differences between true and observed frequencies of consumption of food items. 


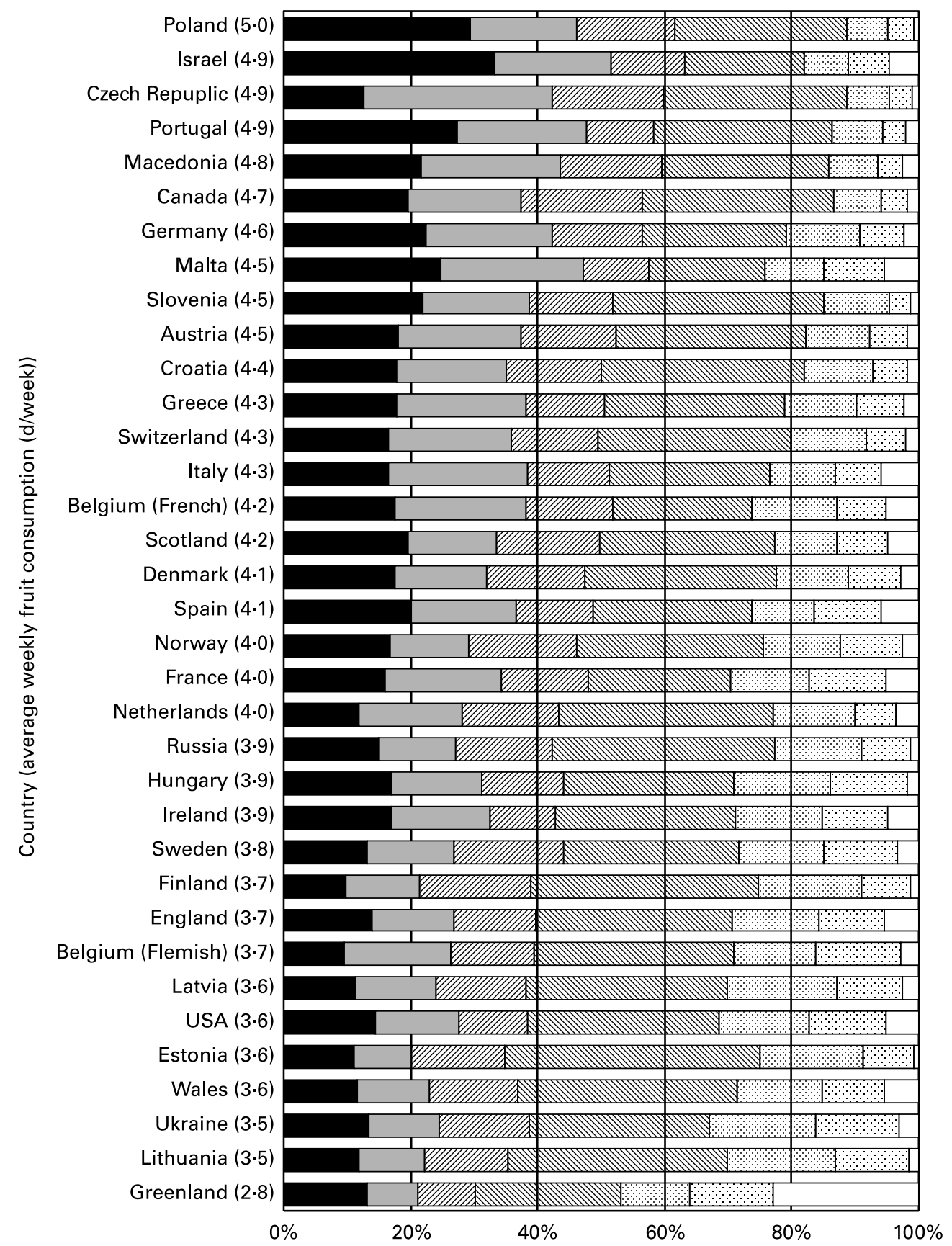

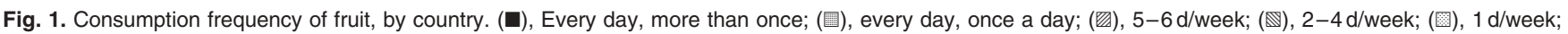
(四), $<1 \mathrm{~d} /$ week; $(\square)$, never.

School participation rates varied substantially between countries: for the twenty-four countries for which response rate was documented, school response varied from $36 \%$ to $100 \%$.

The timing of fieldwork differs from country to country (e.g. in Canada the survey is done in the middle of the winter, whereas in Portugal the survey is done in the spring) so that seasonal differences may affect the consumption of particular food items, such as fruit, vegetables and soft drinks. Although back-translation of the questionnaire into English was used in each country to ensure consistency, there are still likely to be issues of differential interpretation of the questions in different cultures. Moreover, the classification of food items into food groups can be different across countries, leading to impaired comparability. A documented example of this problem is the classification of potatoes in the vegetables group in the USA, while these foods are classified as starchy foods in Europe (Painter et al. 2002).

Different food cultures may affect the validity of the questionnaire in other ways. For example, in southern Europe children often eat vegetables as part of a composite dish (soup, pizza, stew, etc.). However, in these composite dishes vegetables are often not that visible for children, and therefore it might be that they are not considered as vegetables. In a study of Cullen et al. (1999) in the USA, the authors argue that pies, fruit drinks, pizza or other such sources of fruits and vegetable contribute mostly 


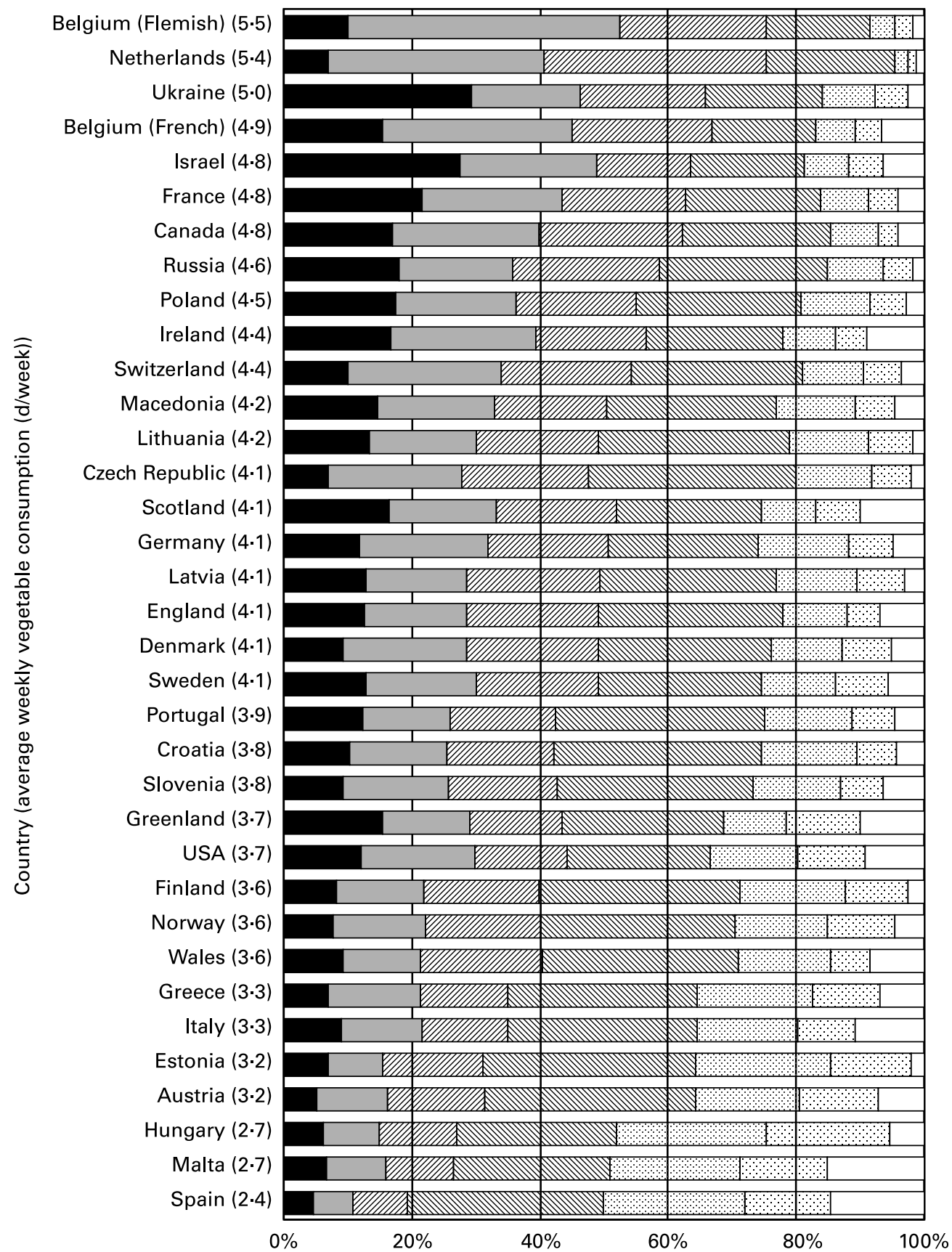

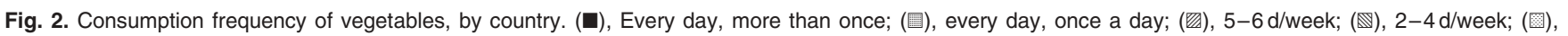
$1 \mathrm{~d} /$ week; (国), <1d/week; ( $\square$ ), never.

energy and should not count towards achieving the recommended portions of fruit and vegetables. Composite dishes in the Mediterranean countries may, however, have a completely different composition than in the USA. Therefore we recommend that validation studies as well as more qualitative studies should be done in culturally divergent countries participating in the HBSC study. Until now only in one participating country (Belgium (Flemish)) has a validation study been done (Vereecken \& Maes, 2003). In the validation study it was concluded that the food frequencies can be used for ranking subjects for most food items, though the use of the frequency questionnaire for translating frequencies of consumption into intake estimations was likely to result in overestimations. It cannot be excluded that other, even opposite, findings could be observed in other countries.

Another limitation is that the pupils were only asked about their consumption frequency and no data were gathered to determine the portion size. However, in general, portion sizes are difficult to estimate accurately, particularly in countries where one is not used to the concept of portion size. In addition, it is not clear from the literature if additional questions on portion sizes in food-frequency questionnaires add substantially to the assessment of dietary intake as some authors find no improvement in relative validity (Margetts et al. 1989; Tjonneland et al. 1992) while others reported an improvement (Block et al. 1990; Jackson 


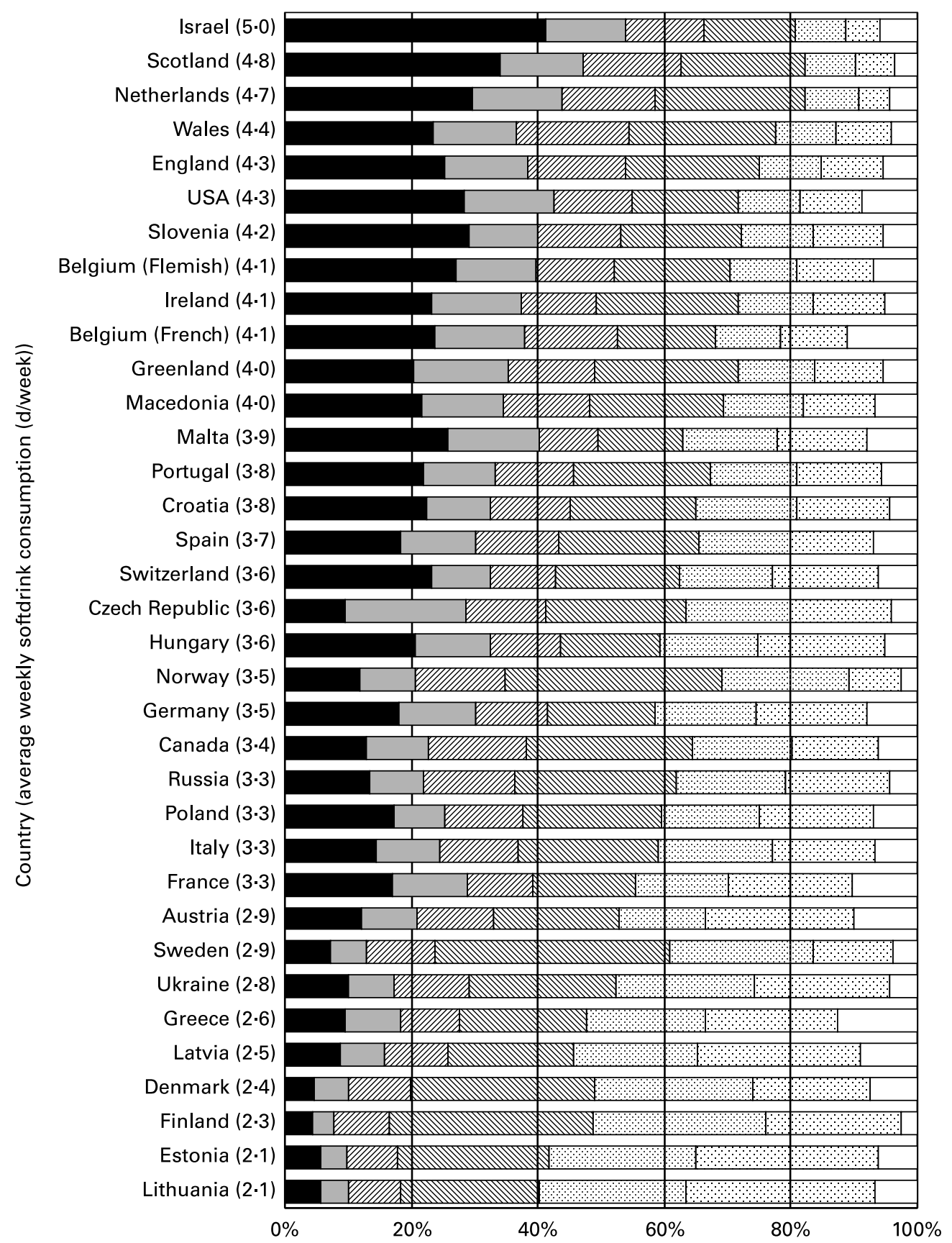

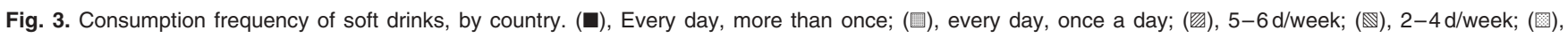

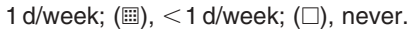

et al. 1990; Kuskowska-Wolk et al. 1992). These studies are, however, done in population groups belonging to the same country. In comparisons between countries, portion sizes of some food items may be more important, as the standard serving sizes may differ across cultures (Biro et al. 2002).

The need to keep the items limited in number means that the study provides only a limited picture of overall eating patterns. However, the European Food Consumption Survey Methods (EFCOSUM) project, aimed at harmonising food consumption surveys in European countries within the perspective of an overall Public Health Monitoring project, confirms that only a limited set of dietary indicators can be selected, governed not only by their relevance to health, but also by the practicality of obtaining reliable and comparable data (Steingrimsdottir et al. 2002). The foods or food groups they selected were fruit, vegetables, bread and fish.

To compare the presented frequencies with other studies is difficult because of differences in methodology, as mentioned earlier. However, consistent with the literature, our present findings show that a significant number of young people consume few fruits and vegetables (Samuelson et al. 1996; Lowry et al. 2002; Aranceta et al. 2003) while sweets, soft drinks (Harnack et al. 1999; Park et al. 2002; Rampersaud et al. 2003), crisps and chips (Kubik et al. 2003), on the other hand, are very popular among adolescents. 


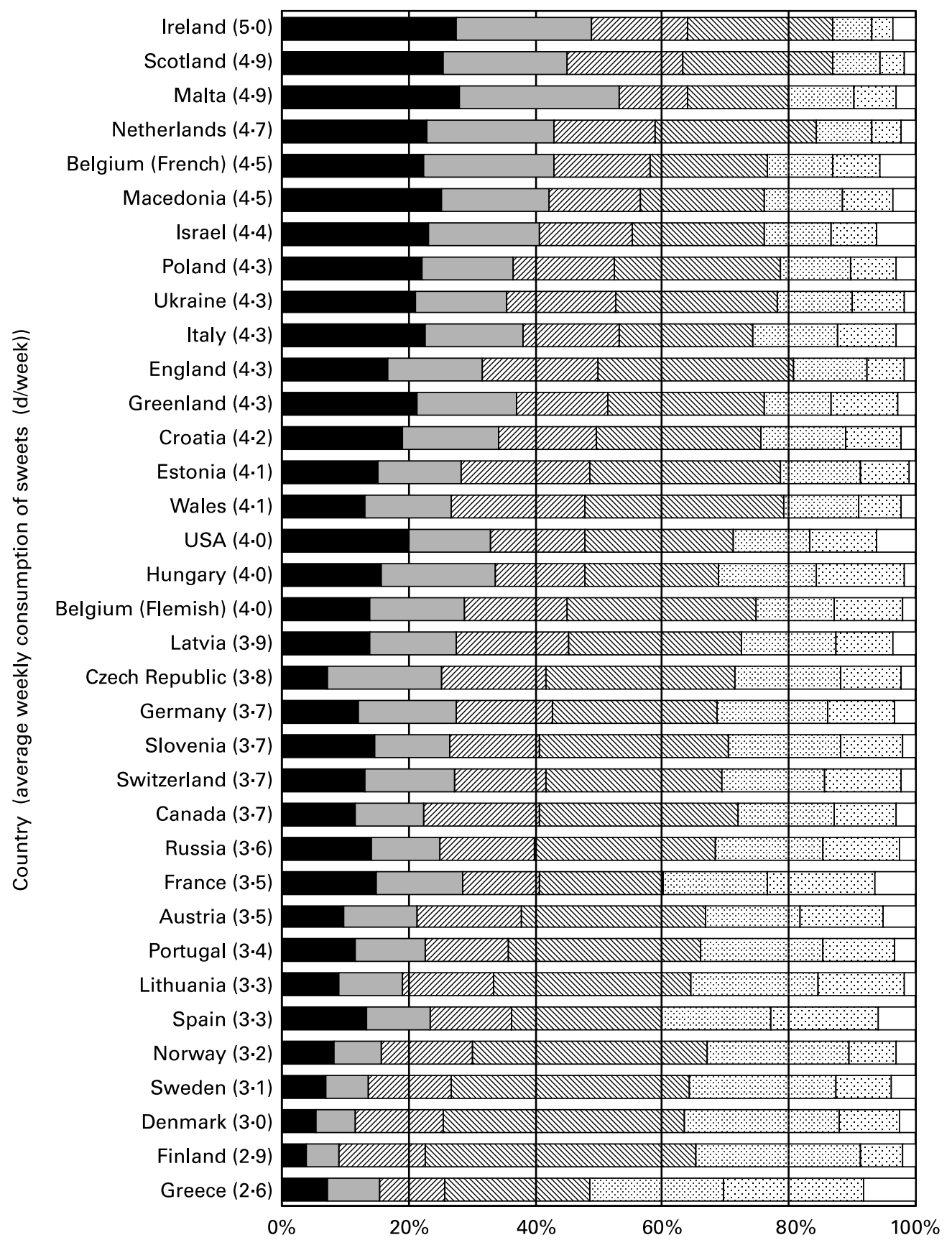

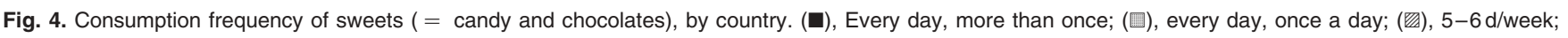

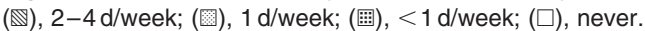

In the present study, the lowest weekly consumption frequency of fruit is found in the most northern isolated country (Greenland); the Baltic States cluster together in the lowest quartile, while all southern countries are in the upper half, as could be expected from a Mediterranean diet including an abundance of plant food. As the latter finding concurs with both a high consumption of fruits and vegetables, it is most surprising to find all south European countries below the median for the consumption of vegetables: Spain and Malta have the lowest average consumption frequencies but also Italy and Greece are in the lowest quartile. This is in contrast with the much higher mean household availability of vegetables found among southern
Europeans, based on the Data Food Networking (DAFNE) project in which daily individual food availability is estimated using data collected in the context of national household budget surveys (Naska et al. 2000; Trichopoulou et al. 2002). These conflicting data might reflect methodological problems or might announce important food transitions in terms of vegetable consumption in Mediterranean countries in the upcoming generations.

Concerning sweet consumption, the clustering of four Nordic countries (Finland, Denmark, Sweden and Norway) in the lowest tertile is striking. The lowest consumption frequencies of soft drinks are found in the countries of the Baltic States, three Nordic countries (Finland, Denmark, Sweden), Greece and 
Table 2. Consumption frequency for the optional Health Behaviour in School-aged Children survey food items, by country

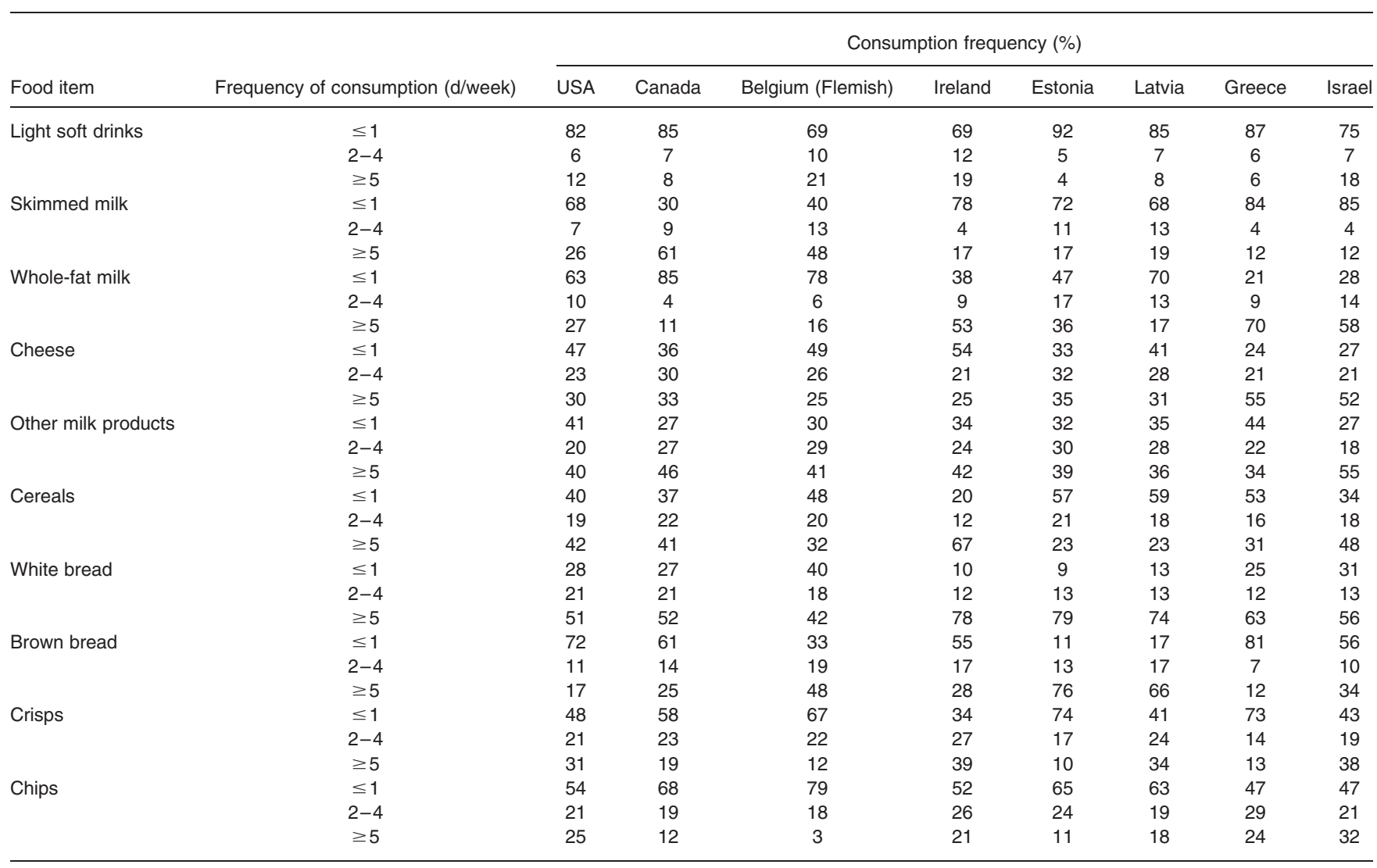

Ukraine, while the highest consumption frequencies are found in Great Britain (Scotland, Wales, England), Ireland, Israel, the Netherlands, the USA, Slovenia and Belgium. Scotland, Wales, England and Ireland are also all above the median for the consumption of sweets.

In conclusion, our present findings indicate a need to promote healthy eating habits among adolescents across Europe, Canada, Israel and the USA. The HBSC study, an international collaborative study, done every 4 years and following a standard protocol, can be a useful tool for national and international health promotion policy, planning and evaluation with respect to the selected food items. However, in comparing consumption frequencies between countries caution is necessary and international validation studies are strongly recommended.

\section{Acknowledgement}

The HBSC survey is a WHO/EURO collaborative study. The international coordinator of the 2001-2 study was Candace Currie, University of Edinburgh, UK; the data bank manager was Oddrun Samdal, University of Bergen, Norway. A complete list of the participating researchers can be found on the HBSC website, http://www.hbsc.org/.

\section{References}

Albertson AM, Tobelmann RC \& Marquart L (1997) Estimated dietary calcium intake and food sources for adolescent females: 1980-92. $J$ Adolesc Health 20, 20-26.
Aranceta J, Perez-Rodrigo C, Ribas L \& Serra-Majem L (2003) Sociodemographic and lifestyle determinants of food patterns in Spanish children and adolescents: the enKid study. Eur J Clin Nutr 57, Suppl. $1, \mathrm{~S} 40-\mathrm{S} 44$.

Barr SI (1994) Associations of social and demographic variables with calcium intakes of high school students. J Am Diet Assoc 94, 260-269.

Barr SI \& McKay HA (1998) Nutrition, exercise, and bone status in youth. Int J Sport Nutr 8, 124-142.

Bellu R, Riva E, Ortisi MT, De Notaris R, Bonacina M, Luotti D \& Giovannini M (1996) Preliminary results of a nutritional survey in a sample of 35,000 Italian schoolchildren. J Int Med Res 24, 169-184.

Bellu R, Riva E, Ortisi MT, De Notaris R, Santiri I, Banderali G \& Giovannini M (1995) Calcium intakes in a sample of 35,000 Italian schoolchildren. J Int Med Res 23, 191-199.

Biro G, Hulshof KF, Ovesen L \& Amorim Cruz JA (2002) Selection of methodology to assess food intake. Eur J Clin Nutr 56, Suppl. 2, S25-S32.

Block G, Woods M, Potosky A \& Clifford C (1990) Validation of a selfadministered diet history questionnaire using multiple diet records. $J$ Clin Epidemiol 43, 1327-1335.

Bronner F (1994) Calcium and osteoporosis. Am J Clin Nutr 60, 831-836. Buts JP \& Absolonne J (1995) Les carences alimentaires chez l'enfant enquete - multicentrique en milieu scolaire. Analyse de l'alimentation quotidienne des adolescents (Food deficiencies in children - multicenter survey in the school environment. Analysis of the daily diet of adolescents). Rev Med Brux 16, 83-88.

Centers for Disease Control and Prevention (1997) Guidelines for school health programs to promote lifelong healthy eating. J Sch Health 67, 9-26.

Chan GM (1991) Dietary calcium and bone mineral status of children and adolescents. Am J Dis Child 145, 631-634.

Crawley HF (1993) The energy, nutrient and food intakes of teenagers aged 16-17 years in Britain. 1. Energy, macronutrients and nonstarch polysaccharides. Br J Nutr 70, 15-26. 
Cruz JA (2000) Dietary habits and nutritional status in adolescents over Europe - Southern Europe. Eur J Clin Nutr 54, Suppl. 1, S29-S35.

Cullen KW, Baranowski T, Baranowski J, Hebert D \& de Moor C (1999) Behavioral or epidemiologic coding of fruit and vegetable consumption from 24-hour dietary recalls: research question guides choice. J Am Diet Assoc 99, 849-851.

Currie C, Samdal O, Boyce W \& Smith B (editors) (2002) Health Behaviour in School-aged Children: A WHO Cross-national Study. Research Protocol for the 2001-2002 Survey. Edinburgh: University of Edinburgh.

Doyle W, Jenkins S, Crawford MA \& Puvandendran K (1994) Nutritional status of schoolchildren in an inner city area. Arch Dis Child 70, 376-381.

Fleming KH \& Heimbach JT (1994) Consumption of calcium in the U.S. food sources and intake levels. J Nutr 124, 1426S-1430S.

Guenther PM (1986) Beverages in the diets of American teenagers. J Am Diet Assoc 86, 493-499.

Harel Z, Riggs S, Vaz R, White L \& Menzies G (1998) Adolescents and calcium: what they do and do not know and how much they consume. $J$ Adolesc Health 22, 225-228.

Harnack L, Stang J \& Story M (1999) Soft drink consumption among US children and adolescents: nutritional consequences. J Am Diet Assoc 99, 436-441.

Jackson N, Little J \& Wilson AD (1990) Comparison of diet history interview and self completed questionnaire in assessment of diet in an elderly population. J Epidemiol Community Health 44, 162-169.

Kelder SH, Perry CL, Klepp KI \& Lytle LL (1994) Longitudinal tracking of adolescent smoking, physical activity, and food choice behaviors. Am J Public Health 84, 1121-1126.

Kersting M, Sichert HW, Alexy U, Manz F \& Schoch G (1998) Macronutrient intake of 1 to 18 year old German children and adolescents. $Z$ Ernahrungswiss 37, 252-259.

Key JD \& Key-LL J (1994) Calcium needs of adolescents. Curr Opin Pediatr 6, 379-382.

Kubik MY, Lytle LA, Hannan PJ, Perry CL \& Story M (2003) The association of the school food environment with dietary behaviors of young adolescents. Am J Public Health 93, 1168-1173.

Kuskowska-Wolk A, Holte S, Ohlander EM, Bruce A, Holmberg L, Adam HO \& Bergstrom R (1992) Effects of different designs and extension of a food frequency questionnaire on response rate, completeness of data and food frequency responses. Int J Epidemiol 21, 1144-1150.

Lowry R, Wechsler H, Galuska DA, Fulton JE \& Kann L (2002) Television viewing and its associations with overweight, sedentary lifestyle, and insufficient consumption of fruits and vegetables among US high school students: differences by race, ethnicity, and gender. $J$ Sch Health 72, 413-421.

Mailhot M, Ghadirian P, Parent ME, Goulet MC \& Petitclerc C (1994) Patterns of calcium intake among French-Canadians living in Montreal. Can J Public Health 85, 351-356.

Margetts BM, Cade JE \& Osmond C (1989) Comparison of a food frequency questionnaire with a diet record. Int J Epidemiol 18, 868-873.

Martinchik AN, Baturin AK \& Helsing E (1997) Nutrition monitoring of Russian schoolchildren in a period of economic change: a World Health Organization multicenter survey, 1992-1995. Am J Clin Nutr 65, 1215S-1219S.

Matkovic V \& Ilich JZ (1993) Calcium requirements for growth: are current recommendations adequate? Nutr Rev 51, 171-180.

Morabia A (1996) From disease surveillance to the surveillance of risk factors. Am J Public Health 86, 625-627.

Moynihan P, Adamson A, Rugg-Gunn A, Appleton D \& Butler T (1996) Dietary sources of calcium and the contribution of flour fortification to total calcium intake in the diets of Northumbrian adolescents. $\mathrm{Br} J \mathrm{Nutr}$ 75, 495-505.

Naska A, Vasdekis VG, Trichopoulou A, et al. (2000) Fruit and vegetable availability among ten European countries: how does it compare with the 'five-a-day' recommendation? DAFNE I and II projects of the European Commission. Br J Nutr 84, 549-556.

Nicklas TA, Myers L \& Berenson GS (1995) Dietary fiber intake of children: the Bogalusa Heart Study. Pediatrics 96, 988-994.

Painter J, Rah JH \& Lee YK (2002) Comparison of international food guide pictorial representations. J Am Diet Assoc 102, 483-489.

Parizkova J (2000) Dietary habits and nutritional status in adolescents in Central and Eastern Europe. Eur J Clin Nutr 54, Suppl. 1, S36-S40.

Park YK, Meier ER, Bianchi P \& Song WO (2002) Trends in children's consumption of beverages: 1987 to 1998. Fam Econ Nutr Rev 14, 69-79.

Rampersaud GC, Bailey LB \& Kauwell GP (2003) National survey beverage consumption data for children and adolescents indicate the need to encourage a shift toward more nutritive beverages. $J$ Am Diet Assoc 103, 97-100.

Rockett HR \& Colditz GA (1997) Assessing diets of children and adolescents. Am J Clin Nutr 65, 1116S-1122S.

Rolland-Cachera MF, Bellisle F \& Deheeger M (2000) Nutritional status and food intake in adolescents living in Western Europe. Eur J Clin Nutr 54, Suppl. 1, S41-S46.

Saldanha LG (1995) Fiber in the diet of US children: results of national surveys. Pediatrics 96, 994-997.

Samuelson G (2000) Dietary habits and nutritional status in adolescents over Europe. An overview of current studies in the Nordic countries. Eur J Clin Nutr 54, Suppl. 1, S21-S28.

Samuelson G, Bratteby LE, Enghardt H \& Hedgren M (1996) Food habits and energy and nutrient intake in Swedish adolescents approaching the year 2000. Acta Paediatr Suppl 415, 1-19.

Sargent RG, Kemper KA \& Schulken E (1994) Dietary behaviors of South Carolina adolescents. J S C Med Assoc 90, 263-269.

Shatenstein B \& Ghadirian P (1996) Nutrient patterns and nutritional adequacy among French-Canadian children in Montreal. J Am Coll Nutrition 15, 264-272.

Spear BA (2002) Adolescent growth and development. J Am Diet Assoc 102, S23-S29.

Steingrimsdottir L, Ovesen L, Moreiras O \& Jacob S (2002) Selection of relevant dietary indicators for health. Eur J Clin Nutr 54, Suppl. 2, S8-S11.

Subar AF, Krebs-Smith SM, Cook A \& Kahle LL (1998) Dietary sources of nutrients among US children, 1989-1991. Pediatrics 102, 913-923.

Tjonneland A, Haraldsdottir J, Overvad K, Stripp C, Ewertz M \& Jensen OM (1992) Influence of individually estimated portion size data on the validity of a semiquantitative food frequency questionnaire. Int $J$ Epidemiol 21, 770-777.

Trichopoulou A, Naska A \& Costacou T (2002) Disparities in food habits across Europe. Proc Nutr Soc 61, 553-558.

Van Poppel G, Schneijder P, Lowik MR, Schrijver J \& Kok FJ (1991) Nutritional status and food consumption in 10-11 year old Dutch boys (Dutch Nutrition Surveillance System). Br J Nutr 66, 161-169.

Vereecken C \& Maes L (2003) A Belgian study on the reliability and relative validity of the Health Behaviour in School-Aged Children food frequency questionnaire. Public Health Nutr 6, 581-588.

Williams CL (1995) Importance of dietary fiber in childhood. J Am Diet Assoc 95, 1140-1149.

Williams CL, Bollella M \& Wynder EL (1995) A new recommendation for dietary fiber in childhood. Pediatrics 96, 985-988. 